\section{Capsule Endoscopy in a Patient with Zenker's Diverticulum}

Capsule endoscopy was recently introduced for endoluminal visualization of the small bowel [1]. The clinical utility of the procedure is undisputed [2-4], and for most patients, swallowing the capsule $(11 \times 33 \mathrm{~mm}$ in size $)$ does not pose any problems.

A 74-year-old woman presented with melena and severe iron-deficiency anemia. She was admitted to the local hospital, where upper endoscopy was initially unsuccessful due to a 3-cm Zenker's diverticulum. A repeat upper endoscopy was carried out the next day; the diverticulum was negotiated during this procedure, but no source of bleeding was found. Colonoscopy revealed only tarry stools and probable small-bowel bleeding. Because of continued bleeding and a need for repeated transfusions, the patient was referred for capsule endoscopy.

A guide wire was initially placed in the stomach to allow visualization of the passage alongside the diverticulum. The capsule was caught in a standard polypectomy snare through the endoscope. However, it was not possible to pass the capsule transversely through the esophageal slit in the diverticulum. Instead, a switch was made to a pediatric endoscope
(Olympus GIF-XP160P, outer diameter $5.9 \mathrm{~mm}$ ) and the capsule was fixed to the outside of the endoscope, approximately $25 \mathrm{~cm}$ from the distal tip, using an external polypectomy snare around the endoscope and the capsule (Figure $\mathbf{1}$ ). The endoscope was then reintroduced into the esophagus and stomach. Passage of the capsule into the stomach was confirmed by retroflex viewing (Figure 2 ), and the capsule was then released. Multiple bleeding angiodysplasias were visualized in several segments of the ileum, and the patient subsequently underwent resection.

In regular cases of difficulty in swallowing the capsule, the standard method of through-the-scope snaring works well. However, the method presented here represents a technically simple alternative in specific cases.

L. Aabakken, J. P. Blomhoff, T. Jermstad, A. B. Lynge

Dept. of Medical Gastroenterology,

Rikshospitalet University Hospital, Oslo, Norway.

\section{References}

${ }^{1}$ Gavriel Iddan G, Meron G, Glukhovsky Aet al. Wireless capsule endoscopy. Nature 2000; 405: 417

2 Ell C, Remke S, May A. The first prospective controlled trial comparing wireless capsule endoscopy with push enteroscopy in chronic gastrointestinal bleeding. Endoscopy 2002; 34: 685-689

${ }^{3}$ Lewis BS. Enteroscopy: endangered by the capsule? Endoscopy 2002; 34: 416- 417

${ }^{4}$ Lewis BS, Swain P. Capsule endoscopy in the evaluation of patients with suspected small intestinal bleeding: results of a pilot study. Gastrointest Endosc 2002; 56: $452-456$

\section{Corresponding Author}

\section{Aabakken, M.D.}

Dept. of Medical Gastroenterology Rikshospitalet University Hospital 0027 Oslo

Norway

Fax: +47-2307-2008

E-mail: larsaa@klinmed.uio.no

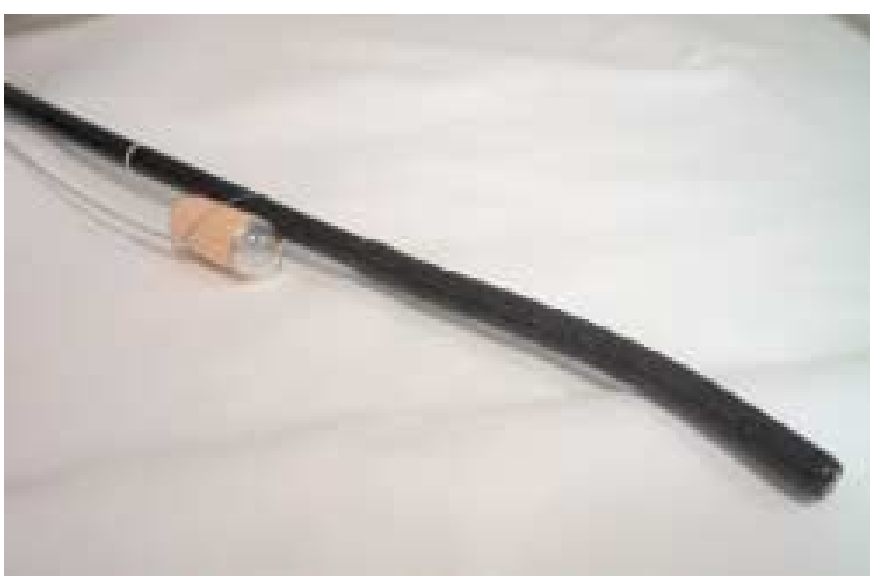

Figure 1 Ex-vivo piggy-back mounting of the capsule onto the endoscope with a polypectomy snare.

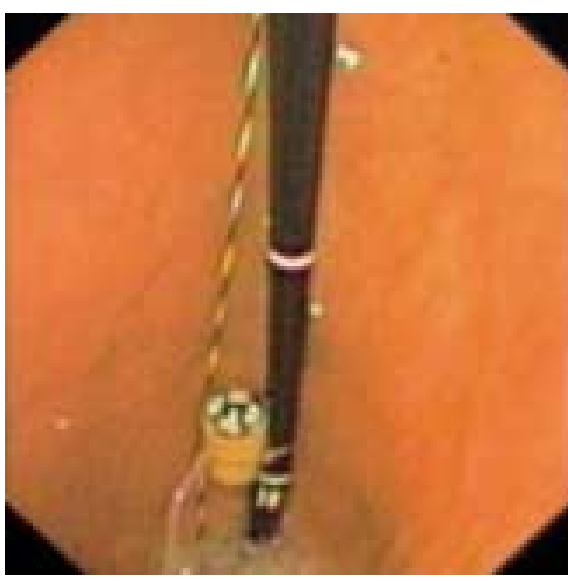

Figure 2 Retroflex view of the capsule in the gastric fundus, ready for release. 